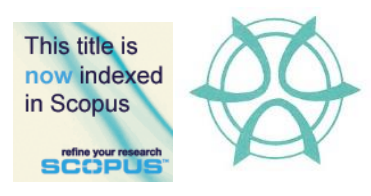

PLANNING MALAYSIA:

Journal of the Malaysian Institute of Planners

VOLUME 16 ISSUE 1 (2018), Page 324 - 333

\title{
PROFILING INTERCITY BUS DRIVERS OF MALAYSIA
}

\author{
Syahriah Bachok', Mariana Mohamed Osman² \& Muhammad Faris Abdullah ${ }^{3}$ \\ ${ }^{1,2,3}$ Kulliyyah of Architecture and Environmental Design, \\ INTERNATIONAL ISLAMIC UNIVERSITI MALAYSIA
}

\begin{abstract}
This research presents a qualitative research output of a profiling study conducted on intercity bus drivers in Malaysia. Some 1200 respondents were approached at one of the main bus termini in Kuala Lumpur, with a set of questionnaire. The analysis focused on describing and elaborating the socio-demographics characteristics of drivers, their working environment and their perception of the current remuneration systems. Investigating these profiles is important as it will contribute to better understanding of this segment of labour market within the transportation industry as well as the examination of factors contributing to drivers' behaviour and its relationships with incidents, accidents or road crashes.
\end{abstract}

Keyword: profiling, intercity bus 
PLANNING MALAYSIA

Journal of the Malaysia Institute of Planners (2018)

\section{INTRODUCTION}

The study on bus drivers' socio-demographics has been scantily published in Malaysia. It is essential that an extensive research on bus drivers' well-being be undertaken in a wider setting to explore, explain and interrelate with some of the events and occurrences such as incidents and accidents involving public transportation vehicles. Not only bus drivers are the first reference points when it comes to investigation of road crashes, they also might be the victims traumatised by such happenings. Public transport vehicles monitoring and regulating have been widely studied elsewhere regionally, globally as well as in Malaysia. However, the drivers, their behaviours, attitudes, perception, actions and aptitudes are not so much elaborated and associated with more positive outcomes of the public transport industry. More often than not, this is an aspect of the transport industry that received the most criticisms, especially when discussing traffic incidents and accidents statistics. Stigmatised by negative perception, lack of positive evaluation and esteem, as well as lower quality working environment, these bus drivers may be reacting, expressing and retaliating against many positive initiatives, policies and schemes introduced the regulatory bodies and agencies. It is therefore, appropriate and timely that a nationwide profiling of bus drivers be made in order to understand, appreciate and propose positive way forwards to improve and upgrade the well-being of bus drivers in Malaysia. In effect, in their hands lay the lives of many public transport and road users.

In recent development of transportation strategies in Malaysia, one of the initiatives were to improve and upgrade the intercity services of buses in the nation. An important facet to such service delivery is the human capital development, which includes training and upskilling of drivers. Intercity services regulating and monitoring lie within the responsibility of an agency under the Prime Minister's Department, known as Land Public Transport Commission (LPTC). Land Public Transport Commission or in Malay, Suruhanjaya Pengangkutan Awam Darat Malaysia (SPAD) is an established agency with numerous jurisdictions and responsibilities related to bus operations under Malaysia Transportation legistlations.

There are several related statutes that govern the industry as a whole and more specifically the sector of bus operators and drivers. These include:

Suruhanjaya Pengangkutan Awam Darat (SPAD) Act 2010 (Act 714), Land Public Transport Act 2010 (Act 715), Commercial Vehicles Licensing Board (Amendment) Act 2010 (Act A1376) and Road Transport Act 1987 (Act 333). These were supported by various rules and regulations such as Road Transport Rules (Compilation of 47 rules). Some departments and agencies like the Malaysia Institute of Road Safety Research also provided standard operating procedures for road safety purposes known as Safety, Health and Environment Code of Practice (SHE COP) (MIROS, 2017). 
Syahriah Bachok, Mariana Mohamed Osman \& Muhammad Faris Abdullah

Profiling Intercity Bus Drivers of Malaysia

The relevant provision ranges from regulating, monitoring, enforcing and prosecuting bus drivers for various reasons such as recklessness of driving, causing death, causing injuries and others. The main ideas were the protection of life, ensuring of safety and security of passengers, penalty for causing harms and the disobedient against rules and regulations governing the public transport operation and road usage. Detailed discussion of the matters is not, however, within the ambit of this research.

Nevertheless, it is worth to point out that regulations on drivers and driving include that limitation of driving duration (8 hours) i.e. Rule 10(B) of Road Traffic Rules 1959, resting durations between two driving shifts/rotations and on-road operation to address driver fatigue, excessive cognitive efforts, circadian rhythms, risk taking behaviours, road rules violation, road safety violations, driving under influence, tailgating, overtaking at prohibited area and speeding. However, none of the provision has been concerned with remuneration, health and medical well-being as well as demoralisation, absenteeism and assaults on drivers by a third party.

It is not purpose of the paper to present statistically significant testing of contributing factors of accidents or crashes with the demographics of these drivers. However, it is the objective of this study to explore, highlight and describe the type of workers who are driving the passengers on the Malaysian road network, their working environment and the type of well-being provided by the companies operating the bus services. Hence, most data presentation and analysis will be only of qualitative and descriptive nature. Nevertheless, the future direction of the industry can be envisaged and forecast through this perspective. In essence, improvement and upgrading of the personal and working life of the bus drivers can be positively promoted so as to increase the drivers' self-esteem, uphold the positive attitude and aptitudes towards passengers' safety and wellbeing and also to revise the most important factor influencing human capital resources performance, namely remuneration packages.

\section{PREVIOUS RESEARCH}

Profiling bus drivers are essential in explaining the existence and quantum of the effect of their socio-economic and demographics characteristics upon awareness, knowledge, aptitude, attitude and behaviours towards incident and accident involving public transport vehicles and other road users.

Previous studies conducted on the relations of driving behaviours and incidents or accidents varied in explaining the primary and mildly contributing factors. Factors such as road geometry, road conditions, weather, opacity, vehicles conditions (interior and exterior), driver behaviours and other road users' behaviours have been discussed by many researchers (Mohamed et al., 2009; Mohd Soid, Isah, \& Liew, 2016; Tse, Flin, \& Mearns, 2006). Even though various factors played contributing roles, many researchers also argued that the 
determinant of many bus crashes and incidents was predominantly drivers' behaviours (Yamada et al., 2008; Biggs, Dingsdag, \& Stenson, 2009). Hence, it is vital that bus drivers be profiled in order to identify possible influence of these characteristics upon awareness and knowledge levels, perception, job satisfaction, aptitude and attitude and most importantly driving behaviour.

In essence, it is also a concern of this research to highlight the statistics of road incidents due to their nature, quantum and impacts on the society; physically, economically and socially.

Table 1: General road accident data in Malaysia (1997 - 2016)

\begin{tabular}{|c|c|c|c|c|c|c|c|c|c|}
\hline Year & $\begin{array}{l}\text { Registered } \\
\text { Vehicles }\end{array}$ & Population & $\begin{array}{c}\text { Road } \\
\text { Crashes }\end{array}$ & $\begin{array}{l}\text { Road } \\
\text { Deaths }\end{array}$ & $\begin{array}{l}\text { Serious } \\
\text { Injury }\end{array}$ & $\begin{array}{l}\text { Slight } \\
\text { Injury }\end{array}$ & $\begin{array}{c}\text { Index per } \\
10,000 \\
\text { Vehicles }\end{array}$ & $\begin{array}{c}\text { Index per } \\
100,000 \\
\text { Population }\end{array}$ & $\begin{array}{c}\text { Indeks per } \\
\text { billion } \\
\text { VKT }\end{array}$ \\
\hline 1997 & $8,550,469.00$ & $21,665,600.00$ & $215,632.00$ & $6,302.00$ & $14,105.00$ & $36,167.00$ & 7.37 & 29.10 & 33.57 \\
\hline 1998 & $9,141,357.00$ & $22,179,500.00$ & $211,037.00$ & $5,740.00$ & $12,068.00$ & $37,896.00$ & 6.28 & 25.80 & 28.75 \\
\hline 1999 & $9,929,951.00$ & $22,711,900.00$ & $223,166.00$ & $5,794.00$ & $10,366.00$ & $36,777.00$ & 5.83 & 25.50 & 26.79 \\
\hline 2000 & $10,598,804.00$ & $23,263,600.00$ & $250,429.00$ & $6,035.00$ & $9,790.00$ & $34,375.00$ & 5.69 & 26.00 & 26.25 \\
\hline 2001 & $11,302,545.00$ & $23,795,300.00$ & $265,175.00$ & $5,849.00$ & $8,680.00$ & $35,944.00$ & 5.17 & 25.10 & 23.93 \\
\hline 2002 & $12,068,144.00$ & $24,526,500.00$ & $279,711.00$ & $5,891.00$ & $8,425.00$ & $35,236.00$ & 4.90 & 25.30 & 22.71 \\
\hline 2003 & $12,819,248.00$ & $25,048,300.00$ & $298,653.00$ & $6,286.00$ & $9,040.00$ & $37,415.00$ & 4.90 & 25.10 & 22.77 \\
\hline 2004 & $13,828,889.00$ & $25,580,000.00$ & $326,815.00$ & $6,228.00$ & $9,218.00$ & $38,645.00$ & 4.52 & 24.30 & 21.10 \\
\hline 2005 & $15,026,660.00$ & $26,130,000.00$ & $328,264.00$ & $6,200.00$ & $9,395.00$ & $31,417.00$ & 4.18 & 23.70 & 19.58 \\
\hline 2006 & $15,790,732.00$ & $26,640,000.00$ & $341,252.00$ & $6,287.00$ & $9,253.00$ & $19,885.00$ & 3.98 & 23.60 & 18.69 \\
\hline 2007 & $16,813,943.00$ & $27,170,000.00$ & $363,319.00$ & $6,282.00$ & $9,273.00$ & $18,444.00$ & 3.74 & 23.10 & 17.60 \\
\hline 2008 & $17,971,907.00$ & $27,730,000.00$ & $373,071.00$ & $6,527.00$ & $8,868.00$ & $16,879.00$ & 3.63 & 23.50 & 17.65 \\
\hline 2009 & $19,016,782.00$ & $28,310,000.00$ & $397,330.00$ & $6,745.00$ & $8,849.00$ & $15,823.00$ & 3.55 & 23.80 & 17.27 \\
\hline 2010 & $20,188,565.00$ & $28,910,000.00$ & $414,421.00$ & $6,872.00$ & $7,781.00$ & $13,616.00$ & 3.40 & 23.80 & 16.21 \\
\hline 2011 & $21,401,269.00$ & $29,000,000.00$ & $449,040.00$ & $6,877.00$ & $6,328.00$ & $12,365.00$ & 3.21 & 23.70 & 14.68 \\
\hline 2012 & $22,702,221.00$ & $29,300,000.00$ & $462,423.00$ & $6,917.00$ & $5,868.00$ & $11,654.00$ & 3.05 & 23.60 & 13.35 \\
\hline 2013 & $23,819,256.00$ & $29,947,600.00$ & $477,204.00$ & $6,915.00$ & $4,597.00$ & $8,388.00$ & 2.90 & 23.10 & 12.19 \\
\hline 2014 & $25,101,192.00$ & $30,300,000.00$ & $476,196.00$ & $6,674.00$ & $4,432.00$ & $8,598.00$ & 2.66 & 22.00 & 10.64 \\
\hline 2015 & $26,301,952$ & $31,190,000$ & 489,606 & 6,706 & 4,120 & 7,432 & 2.55 & 21.5 & 9.6 \\
\hline 2016 & $27,613,120$ & $31,660,000^{\circ}$ & $521466^{a}$ & $7152^{a}$ & NA & NA & 2.59 & 22.6 & NA \\
\hline
\end{tabular}

Source: Malaysia Institute of Road Safety Research, 2017

From the Table above, number of crashes has been on the increased annually since 1998, with total death rates fluctuating from 1998 and 2000, but increasing ever since (peaking at 7,152 deaths in 2016). Supporting this trend are two other research by MIROS (2017), indicating that fatality involving bus crashes are on the rise, whereby some 236 deaths were recorded in 2006, 41 bus incidents involving deaths (2007 and 2008), 131 bus incidents with 62 of them with death cases (2012) and among the most tragic one being the 2014 case where 37 deaths occurred in a single trip at Genting Highlands.

\section{DATA COLLECTION AND ANALYSIS}

This research was carried out on some 1200 intercity bus drivers, having an origin or a destination of the trip at the Terminal Bersepadu Selatan (Southern Integrated Bus Terminal), located in Kuala Lumpur, Malaysia. The geographical routes and paths of buses were conveniently selected and therefore would not be discussed 
Syahriah Bachok, Mariana Mohamed Osman \& Muhammad Faris Abdullah

Profiling Intercity Bus Drivers of Malaysia

as these are not within the ambit of the research. A survey questionnaire was carried out on the bus driver (if single driver) or the main bus driver (if and when there existed two or more drivers per unit of bus), similarly based on convenient sampling.

The questionnaire was divided into four main parts namely, demographics, work or job details, remuneration and other benefits as well as comments or remarks made on the current working conditions.

\section{Profiling the Demographics of Bus Drivers.}

The majority (99\%) of the drivers were male, aged between 41 and 50 years old (35\%). Most (88\%) were Malay drivers with $10 \%$ Indian and some 2\% percent were of Chinese ethnicity. The majority $(55 \%)$ were secondary school leavers or SPM (Secondary Education Certificates) holders, (54\%) earning on average between RM2000 - RM2999 (USD 450 - 750) monthly.

\section{Work Environment}

A large (51\%) proportion of the respondents were on average, having a driving duration less than 8 hours, excluding commuting hours to and from their homes. On average too, $(35 \%)$ many drivers were having between 6 to 10 years driving experiences. Analysing the turnover rate data, it can be deemed that the loyalty towards a company/firm is not a policy among these drivers because as many as $822(69 \%)$ of them have changed employers in the course of their employment history. Some $122(10 \%)$ even had changed employment three times or more.

In observing the $10 \mathrm{~B}$ rules, companies were allocating at least 30minutes rest in between shifts or rotations for most drivers (97\%), however, wages or salary structure is not supporting the economic well-being of these drivers. In many cases they were forced to play catch up with as many trips as possible since salaries are based on these structures (63\% monthly based, $11 \%$ daily based). Further investigation revealed that the $63 \%$ of monthly based remuneration was actually monthly-trip combination based.

\section{Remuneration Packages}

Nevertheless, some $(45 \%)$ the companies or operators provided commission allowances and other additional incentives $(21 \%)$. These additional incentives ranged from employee's provident fund $(90 \%$ of respondents reported to have received this), Workplace Occupational Hazards and Impairment benefit (90\%), Family benefits upon one's Death (35\%), School benefits for employee's children (26\%), medical benefit (39\%) and other types of benefits (1\%) including: umrah (non-obligatory pilgrimage to Makkah), hotel, insurance, uniform, medical, goodwill fund. Some drivers (43\%) did not receive any of these benefits from the employers. 
PLANNING MALAYSIA

Journal of the Malaysia Institute of Planners (2018)

Prior and during employment, many drivers received some forms of training. For instance, $60 \%$ of them went through drivers' training courses and safety courses (62\%). While the majority of drivers indicated in the earlier paragraph that driving duration was within the stipulated regulation of Rule 10B, it was a surprise to find that some $5 \%$ of drivers were working more than 12 hours a day, presumably on double shifts or due to overtime or even for replacing absenteeism. Drivers have been making remarks that the industry was losing many employees due to unattractive remuneration system and low quality work environment, not to mention the negative perception that the government agencies and the public have on their persons and personality. Their words, "we are not criminals, we are drivers", "we are not criminals, please understand us" are some of the examples of how stigmatised are the job and the persons undertaking the job. Of the $34 \%$ drivers approached who complained about their well-being, the majority issues raised were remuneration, benefits in cash and in kind, absence of health and other insurance, poor road, vehicle and working conditions, antagonistic government agencies or unsympathetic employers, passengers' rude and inappropriate behaviours, difficulties of obtaining necessary permits as well as stingy employers when dealing with cash advancement for trip expenses. These 408 drivers also complained about the need for speeding, and the pre-conceived notion that drivers were the culprit for many bus accidents.

Turnover rates were gloomy for this industry. With the current company, drivers' service duration can be categorised as follows: 0 to 7 years (75\%), 8 to 17 years $(20 \%), 18$ to 27 years $(0.4 \%), 28$ to 37 years $(0.06 \%)$ and one driver even has started working since 1959.

Drivers surveyed reported that company hopping was a norm in the industry. $91 \%$ drivers were working with one single company, but only $29 \%$ have stayed more than 10 years with the same employer. Some $32 \%$ had until currently been working for two companies, those staying with the same employers for 10 years or more were only $4 \%$. Some $10 \%$ drivers had been working under three different companies during different time frame, and only $0.06 \%$ stayed with the same employer for more than 10 years.

\section{DISCUSSION}

There is a plethora of research focusing on profiling, but most are foreign based, especially in the developed countries. For example, in the United States, drivers were also majority male (74\%), with a mean age of 47 , having a mean driving experience of 8 years, married (65\%), possessing only high school education certificates (44\%), having a mean driving hours per week of 37.14 hours, driving schedule being divided into (62\%) daytime, (9\%) night time and manning a vehicle aged an average of 9.5 years (D’Souza \& Maheshwari, 2013). When facing assaults or harassment, some employers trained drivers in martial arts, for instance, Aikido. 
Syahriah Bachok, Mariana Mohamed Osman \& Muhammad Faris Abdullah

Profiling Intercity Bus Drivers of Malaysia

In the United Kingdom, a similar profiling was gathered. Drivers were of the average age of 46 years old, majority (93\%) male, having an average length of service of 10 years, working on a weekly 39 hour basis, did not consider the job was good for their health (74\%) (Jones, Haslam, \& Haslam, 2014). Both studies reflected the labour market situation of this segment of the industry, which fits the Malaysian profiles too.

Rusco and Walls (2005) argue that remuneration package of drivers were determined by level of economic development, people's income, region and passengers' population. They asserted that salary influenced behaviour, while behaviour influenced safety and quality of services. Various remuneration structures were identified for these developing cities. Hanoi has a fixed salary plus bonus payment for fuel consumption structure, Yangon adopted the share of fare revenue, fixed salary plus bonus system based directly on bus fare revenue structure, Bangkok subscribed to fixed salary plus bonus based directly on bus fare revenue structure, Jakarta used the fixed percentage of total fare revenue, fixed salary plus bonus based directly of bus fare revenue structure and finally Santiago adopted the fixed percentage of total fare revenue structure (Htun, Nakamura, Okamura, \& Wang, 2012). None of these structure resembles that of Malaysian bus drivers' packages. In Malaysia, trip basis was more superior than passenger counts.

Rusco and Walls (2005) propagate that remuneration has various effects on behaviour: lack of quality remuneration would lead to symptoms of poor driving quality, aggressive driving behaviour, caused by weakness in enforcement of regulation and inadequate penalty system. Additionally, poor safety standard, shortage of skills, poor educational standard of drivers, limited training facilities are also the features of many developing cities' bus drivers' working environment. It was recommended that revenue control procedure (based on number of passengers) be placed, as well as a revamp of training and appropriate incentives (Rusco \& Walls, 2005). Malaysian case study possesses many of these features and may learn from the best practice examples cited in the literature.

Yamada et al. (2008) profiled bus drivers in Chiba, Japan. 100\% bus drivers were male, with an average age of 40.2 years old, having a duration of service 4.5 years. They highlight that there existed 10 job stresses: the lack of worth doing the job, the declining feeling of aptitude for the job, the bad environment in a bus, the bad environment in a company, the trouble in human relations, the difficulty of taking rest or holidays, the inappropriate salary or promotion, the punctuality of timetable, the low evaluation from company and the complaints from passengers (Yamada et al., 2008). They argue that fatigue and sleepiness led to accidents. It was recommended that improved reward system, positive work evaluation and increased private time with family and friends would motivate bus drivers (Yamada et. al, 2008). The Malaysian case 
study has exhibited the same complaints by bus drivers. Therefore, it is also appropriate to subscribe to the recommendations made by Yamada et al. (2008).

On the local front, Mohamed et al. (2009) found that accidents peaked at 0300-0500 and 1400-1500 hours, indicating fatigue and sleepiness as contributing factors to crashes. In an interview of 16 drivers, Mohamed et al. (2009) found that drivers were of age ranged between 40-59 years old, possessing experience of 5 to 30 years, drove long distance of more than $300 \mathrm{~km}, 60 \%$ of the them were driving in the wee hour (12midnight to $6 \mathrm{am}$ ). Further investigation discovered that drivers earned a basic salary of RM300 to RM700 (USD 75 - 180), with an allowance of RM70 to RM91 (USD 18 - 23) per trip and were making 15-18 trips per month. Average monthly salary was RM1,500 to RM2,000 (USD375 - 500), which increased during the festive month to around RM2,500 - RM3,500 (USD $600-850$ ), with $50 \%$ of the remuneration coming from wee hour trips. There was no resting place provided and parking lot were haphazardly provided that drivers were often slapped with parking tickets at the end of a trip (Mohamed et al., 2009). It was recommended that salaries be revised to compensate for income loss, accommodation be provided for wee hour trips, parking lots be provided for buses (Mohamed et al., 2009). The authors also found that $15 \%$ accidents occurred due to fatigue or falling asleep. Sleep deficiency resulting from extended the work day by as much as 3 hours are taking the tolls on safety and work quality (Biggs, Dingsdag, \& Stenson, 2009). Similar complaints have been made by some of the 1200 respondents of this study. They were compromising their rest and sleep time in order to make the possible maximum trip number per day to compensate for any loss of income due to other reasons.

In a more recent study, Mohd Soid, Isah and Liew (2016) profiled bus drivers as $100 \%$ male, (34\%) aged between $46-55$ years old. They also found that some $31 \%$ were with a driving experience less than 5 years, $24 \%$ were with more than 20 years (24\%). Majority ( $82 \%$ ) drivers had 4 to 6 days working in a week, (72\%) possessed only secondary school certificates, $(85 \%)$ were driving hours 8 hours or below while a small percentage (15\%) was driving between 9 to 16 hours (Mohd Soid et al., 2016). The authors recommended that bus companies or operators provide drivers' training, agencies to tighten the enforcement, employers to provide more direct incentives and cash rewards. They observed that speeding behaviours among drivers were rampant if no enforcement officer was on board, or if the bus departed beyond the scheduled/published departure time (Mohd Soid, Isah, \& Liew, 2016).

On the international front, Tse, Flin ad Mearns (2006) argue that drivers were made liable to suffer ill health as a result of the job. As a result, the industry faced over a billion dollars lost a year to unscheduled absenteeism (for medical reason). The authors defined burnout as high absenteeism, sick days, healthcare costs, negligence on the job, lowered morale and poor customer interactions which are currently faced by many bus drivers in the global context (Tse, Flin, \& 
Syahriah Bachok, Mariana Mohamed Osman \& Muhammad Faris Abdullah

Profiling Intercity Bus Drivers of Malaysia

Liew, 2006). Similar remarks have been made by some of 1,200 respondents of this research.

To conclude, the job of a bus driver in Malaysia is an inferior one, manned by unskilled labourers, with lower education levels and simultaneously lower disposable income to bring home. Even though is not categorised as 3D job (Dirty, Difficult and Dangerous), the responsibility that each bus driver is holding is as heavy as those of the former, due to the number of passengers and the risks upon livelihoods while making that trip on that particular public transport vehicle. It is a job of last resort, with lack of security, low cash and fringe benefits, high turnover rates, low morale and low levels of loyalty among workers towards the bus operators/companies. Carrier development is definitely absent in this industry and negative views by the public may be realistically perceived by the drivers.

Unless the following recommendations are heeded, many of these drivers will leave the industry as quickly as they enter this sector of job market. Those remained will be of lesser than the required quality and almost essentially demotivated to stay put in the industry for the longer term benefits.

\section{RECOMMENDATIONS}

It is not the aim of this research to detail out the panacea for the bus driver industry, but rather a targeted remedial actions that can be mooted in both the shorter and medium terms. The recommendations focus on the review and improvement of the followings in ensuring the socio-economic well-being of the drivers are safeguarded:

1. Remuneration packages and loyalty',

2. Cash incentives and direct rewards,

3. Training and retraining especially regarding road safety rules and regulations,

4. Driving duration and interior bus condition,

5. Enforcement of road rules and regulations by physical presence/appearance of an officer, road marking, shared penalty burdens among drivers and companies, and

6. Medical and health insurances, and other benefits in kind.

Details remuneration packages, cash and incentive rewards have been discussed in the previous section. However, training packages, traffic safety, road rules and regulations are all included in the SHE COP prepared by MIROS (2017). It left medical, health insurance and other benefits for the drivers' wellbeing as the new areas to be explored, opening up for wider research horizon in the future. 
PLANNING MALAYSIA

Journal of the Malaysia Institute of Planners (2018)

\section{ACKNOWLEDGEMENT}

The authors are indebted to International Islamic University Malaysia Entrepreneurship and Consultancy Sdn. Bhd. (IEC) for the support on this research paper.

\section{REFERENCES}

Biggs, H., Dingsdag, D., \& Stenson, N. (2009). Fatigue factors affecting metropolitan bus drivers: A qualitative investigation work. A Journal of Prevention, Assessment, and Rehabilitation, 32(1), 5-10.

D’Souza, K., \& Maheshwari, S. (2013). A research framework for studying transit bus driver distraction, Final Report. Eastern Seaboard Intermodal Transportation Application Centre, Hampton University, Hampton.

Htun, P. T. T., Nakamura, F., Okamura, T., \& Wang, R. (2012). Influences of bus drivers' salary system on their behaviour. Asian Transport Studies, 2(2), 209-220.

Jones, W., Haslam, R., \& Haslam, C. (2014). Measuring job quality: a study with bus drivers. Applied Ergonomics, 45(6), 1641-1648.

Malaysia Government (various years). Various acts.

Malaysian Institute of Road Research [MIROS] (2017). www.miros.gov.my

Mohamed, N., Mohd Yusoff, M. F., Othman, I., Zulkifli, Z. H., Osman, M. R., \& Wong, S. V. (2009). An impact assessment of banning wee-hour express bus operation, MRR 10/2009. Kuala Lumpur: Malaysian Institute of Road Safety Research.

Mohd Soid, N. F., Isah, N., \& Liew, S. (2016). Express bus drivers attitude towards traffic safety and inappropriate driving behaviour, MRR 196/2016. Kuala Lumpur: Malaysian Institute of Road Safety Research.

Rusco, F. W., \& Walls, W. D. (2005). Choice of driver contract in road transport. Journal of the Eastern Asia Society for Transportation Studies, 6, 3915-3924.

Tse, J. L. M., Flin, R., \& Mearns, K. (2006). Bus driver well-being review: 50 years of research. Transportation Research Part F: Traffic Psychology and Behaviour, 9(2), 89-114.

Yamada, Y., Mizuno, M., Sugiura, M., Tanaka, S., Mizuno, Y., Yanagiya, T., \& Hirosawa, M. (2008) Bus drivers' mental conditions and their relationship to bus passengers' accident with a focus on the psychological stress concept. Journal of Human Ergology, 37(1), 1-11. 